\title{
Unusual Congenital Lesion Masquerading as a Lung Mass in an Adult
}

\author{
Vartika Singh ${ }^{1}$ Kotian Shravya Sudhesh ${ }^{1}$ Kishan Prasad H.L. ${ }^{1}$ Giridhar Belur Hosmane ${ }^{2}$ \\ Mundayat Gopalakrishnan ${ }^{3}$ Jayaprakash Shetty K. ${ }^{1}$
}

${ }^{1}$ Department of Pathology, K.S. Hegde Medical Academy, Nitte (Deemed to be University), Mangalore, Karnataka, India

2 Department of Pulmonary Medicine, K.S. Hegde Medical Academy,

Nitte (Deemed to be University), Mangalore, Karnataka, India

${ }^{3}$ Department of CTVS, K.S. Hegde Medical Academy, Nitte (Deemed to be University), Mangalore, Karnataka, India

J Health Allied Sci ${ }^{N U} 2022 ; 12: 217-220$.
Address for correspondence Kishan Prasad H.L., MBBS, MD, Department of Pathology, K.S. Hegde Medical Academy, Nitte (Deemed to be University), Mangalore 575018, Karnataka, India (e-mail: kishanprasadhl@nitte.edu.in).

\begin{abstract}
Keywords

- congenital pulmonary airway malformation

- cystic

- bronchoalveolar

Congenital pulmonary airway malformation (CPAM) is a broad spectrum of congenital cystic lung lesions caused by the arrested bronchoalveolar development. Approximately, $80 \%$ of CPAMs are diagnosed prenatally or during the neonatal period when patients present with respiratory failure and cyanosis. CPAM is often associated with other organ anomalies and aplasia, and they have poor prognoses. Many CPAMs are detected in infants and school-age children, and infections like pneumonia trigger these diagnoses. It rarely manifests in adults. These often get missed because of the superadded diseases, and hence, it is essential to have a correct approach to their diagnosis to avoid misdiagnosis.
\end{abstract}

\section{Introduction}

Congenital pulmonary airway malformation(CPAM), previously known as congenital cystic adenomatoid malformation, is a rare congenital disorder of childhood affecting neonates and infants. ${ }^{1}$ It is caused by the bronchoalveolar developmental arrest with the proliferation of the terminal respiratory units in the affected lobe. ${ }^{2}$ As the air gets entrapped, it leads to the cystic dilatation of the bronchioles. ${ }^{3}$ It has an incidence of 1 in 25,000 to 35,000 population. ${ }^{4}$ These lesions manifest with recurrent pneumonia and severe respiratory distress. ${ }^{1}$ These cases can be detected during routine prenatal ultrasonography (USG). ${ }^{1,4,5}$ Very rarely, they can remain undetected until adulthood, when the patient starts showing nonspecific lower respiratory tract symptoms. ${ }^{6}$ Stocker et al have divided CPAM into five subtypes based on morphology and microscopy, with type 1 being the most common subtype., ${ }^{7,8}$ Biopsy plays a vital role in confirmation. ${ }^{1-8}$ Grossly, they show single or multiple cystic spaces. On microscopy, varying sized microcystic spaces lined by ciliated, cuboidal to columnar epithelium along with inflammatory infiltrates, are seen. ${ }^{5-9}$ Lobectomy is the preferred treatment of choice and is considered life-saving. ${ }^{10}$ CPAM holds a good prognosis after lobectomy. However, incomplete resection can lead to recurrence. Rare cases of patients developing adenocarcinomas after resection have also been reported. ${ }^{3}$ Here, we report a rare case of CPAM in a $40-$ year-old woman who remained undetected until lately when she started having high-grade fever and associated cough.

\section{Case Report}

A 40-year-old female with no previous comorbidities presented with cough with expectoration and high-grade fever for 6 months, which aggravated for the past 10 days. The
DOI https://doi.org/ $10.1055 / \mathrm{s}-0041-1736281$. ISSN 2582-4287.

\footnotetext{
(c) 2021. Nitte (Deemed to be University). All rights reserved. This is an open access article published by Thieme under the terms of the Creative Commons Attribution-NonDerivative-NonCommercial-License, permitting copying and reproduction so long as the original work is given appropriate credit. Contents may not be used for commercial purposes, or adapted, remixed, transformed or built upon. (https://creativecommons.org/ licenses/by-nc-nd/4.0/)

Thieme Medical and Scientific Publishers Pvt. Ltd., A-12, 2nd Floor, Sector 2, Noida-201301 UP, India
} 


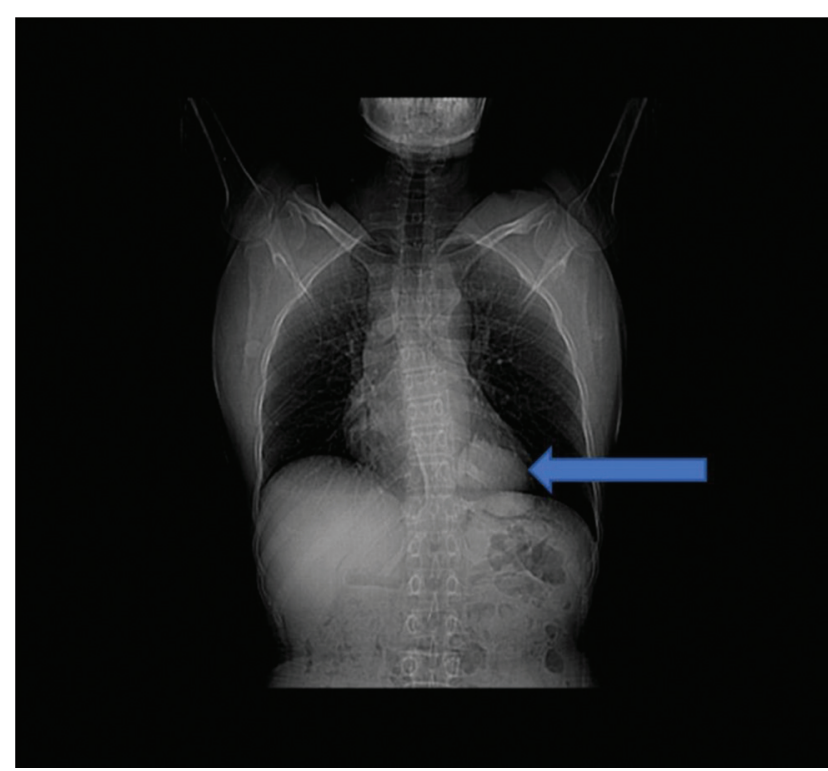

Fig. 1 Chest X-ray of left lower lobe opacity.

expectorant was whitish with no bloodstain. The chest X-ray showed well-defined opacity in the left lower zone near the cardiophrenic region (-Fig. 1). On contrast-enhanced computed tomography scan, thorax, a well-defined, rounded, thin-walled, hypodense, nonenhancing uniloculated cystic lesion measuring $6 \times 4.8 \times 4.5 \mathrm{~cm}$ was seen-the posterior basal segment of the left lower lobe with no surrounding consolidation (-Fig. 2). A possibility of the bronchogenic cyst was considered based on imaging; however, certain differentials were also considered, such as hydatid cyst, esophageal duplication cyst, and sequestration cyst. Bronchoscopy findings were unremarkable.

An elective left lower lobectomy was performed. Grossly, the left lobectomy specimen measured $17 \times 8 \times 6 \mathrm{~cm}$ with a cyst on the posterior surface. A hematoma was also seen on the upper portion. Cut surface showed a solitary cyst measuring $8 \times 5 \times 4.5 \mathrm{~cm}$ exuding purulent material in the lung parenchyma. There were no septations noted (-Fig. 3 ). Microscopy showed an intraparenchymal cyst lined by ciliated columnar respiratory epithelium having a uniform

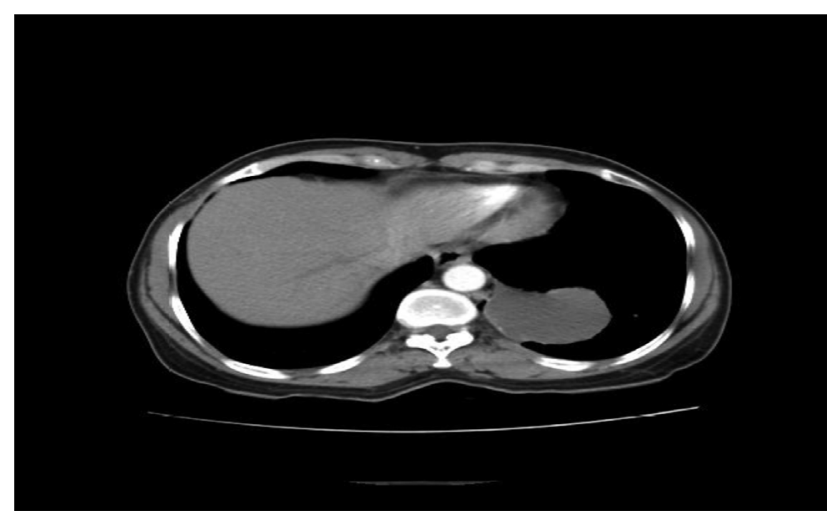

Fig. 2 Contrast-enhanced computed tomography scan of thorax: well-defined rounded, hypodense, thin-walled nonenhancing uniloculated lesion-posterior basal segment of the left lower lobe.

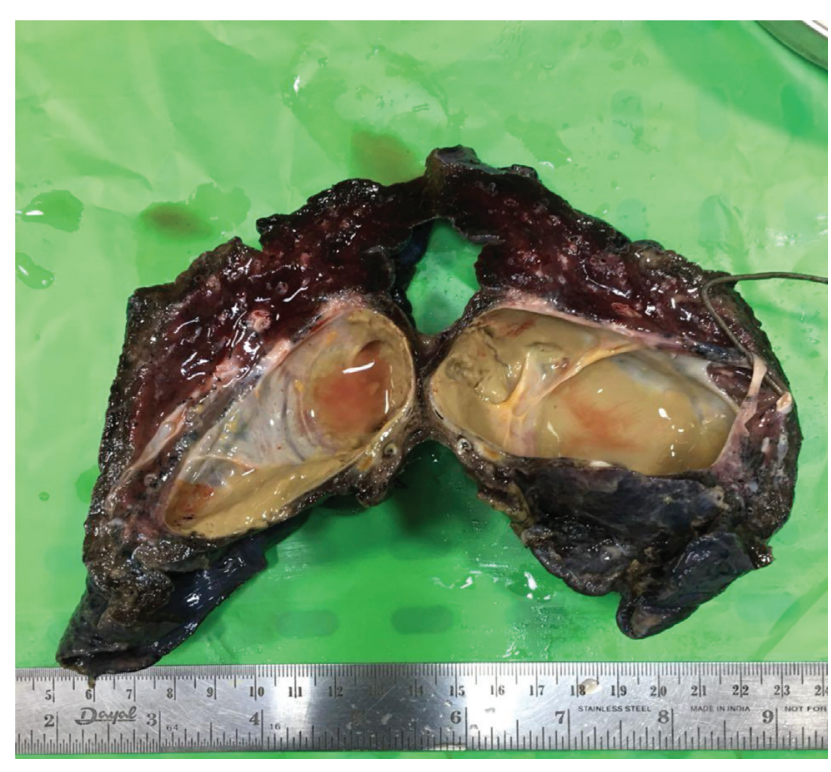

Fig. 3 Gross findings: Left lobectomy specimen with a large cyst measuring $8 \times 5 \times 4.5 \mathrm{~cm}$. The cyst has a glistening appearance. Adjacent lung parenchyma is spongy and hemorrhagic.

nucleus (-Figs. 4-6). Adjacent lung parenchyma showed tiny cystic spaces lined by cuboidal to columnar epithelium with a uniform nucleus containing serous secretions. Also areas of hemorrhage and scattered chronic inflammatory cells were noted. The cyst had proteinaceous material. Diagnosis of CPAM-type 2-left lower lobe was made. On subsequent follow-up, the patient recovered well.

\section{Discussion}

The CPAM is a rare and complex congenital anomaly resulting from the failure of normal bronchoalveolar development

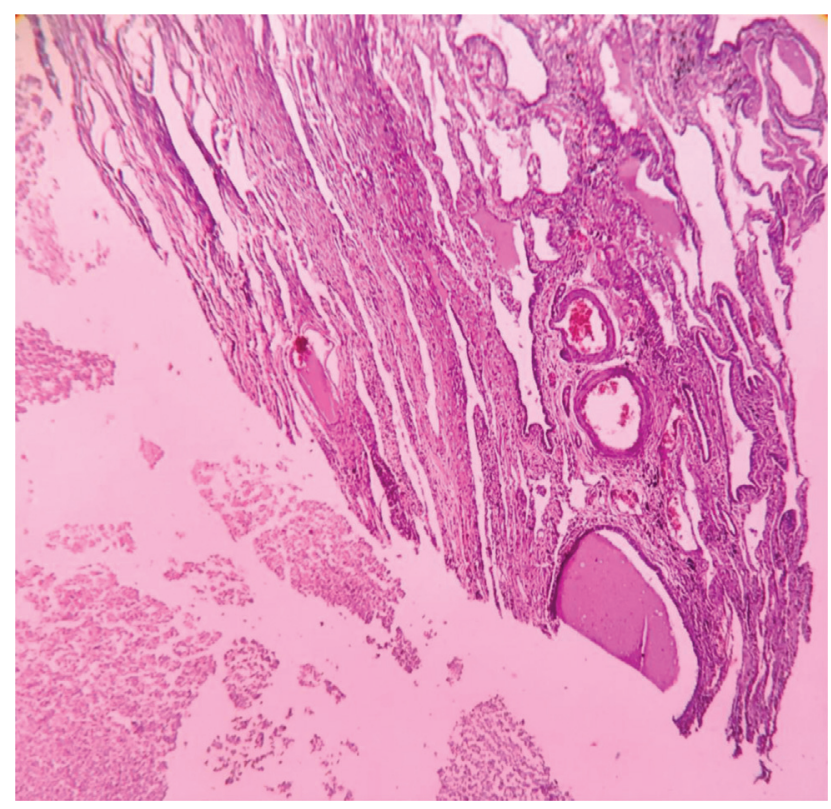

Fig. 4 Microscopic findings: Cyst containing serous secretions and lined by ciliated columnar epithelium having a uniform nucleus ( $4 \mathrm{x}$, hematoxylin and eosin). 


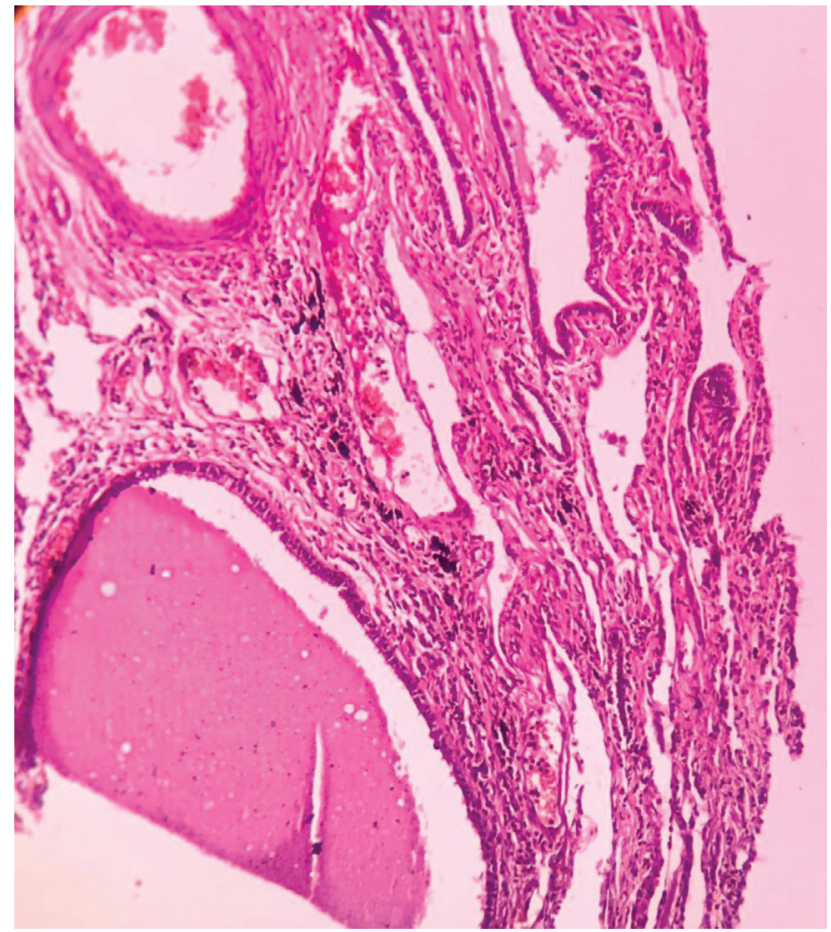

Fig. 5 Microscopic findings: Intraparenchymal cyst (10x, hematoxylin and eosin).

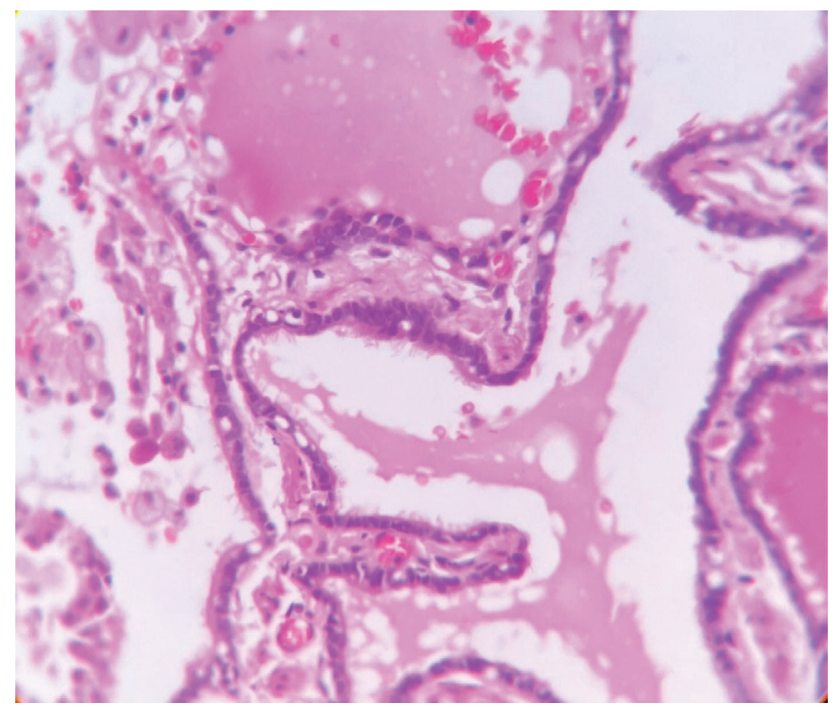

Fig. 6 Microscopic findings: Cyst with ciliated columnar lining epithelium (40x, hematoxylin and eosin). with the hamartomatous proliferation of terminal bronchioles in a gland-like pattern (adenomatoid). ${ }^{1-3}$ It is usually diagnosed either prenatally or within the first 2 years of life (90\% cases) and may cause severe respiratory distress in newborns and infants. ${ }^{1,5}$ They are usually solitary and involve a single lobe. ${ }^{8-12}$ Based on morphology and microscopy, Stocker et al classified it into five subtypes in $2002 .^{6-8}$ Type 0 CPAM (acinar dysplasia) is composed of cartilaginous airways, type 1 has $>2 \mathrm{~cm}$ cysts lined by ciliated columnar epithelium-the most common type, type 2 have $<2 \mathrm{~cm}$ cysts resembling ectatic irregular bronchioles (second most common), type 3 is primarily solid lesion resembling pulmonary hyperplasia, and type 4 is composed of a large peripheral cyst lined by alveolar epithelium. ${ }^{3,8}$ USG allows early detection during the second trimester of pregnancy as cystic and hyperechoic fetal lung lesions. ${ }^{1-5}$ However, very rarely, they can go undetected until adulthood. Our patient has remained asymptomatic for around 40 years until she developed recurrent lower respiratory tract infections. Detailed clinical examination revealed no associated congenital deformities. Salient clinicopathological characteristics of infant and adult CPAM are shown in - Table 1.

The diagnosis of CPAM presenting in an adult can easily be missed. Hence, it is essential to distinguish CPAM from the broad spectrum of congenital pulmonary malformations like bronchogenic cysts, giant bulla, bronchopulmonary sequestrations, bronchiectasis, congenital lobar emphysema, and bronchial atresia. ${ }^{5}$ Chest computed tomography (CT) might be a better diagnostic modality than X-rays for cystic lung diseases, but biopsy helps to confirm the diagnosis. ${ }^{5-10}$ In our case, based on the chest X-ray and CT findings of nonenhancing uniloculated cystic lesion in the posterobasal segment, the bronchogenic cyst was the most probable diagnosis. Lobectomy is most commonly preferred in patients with CPAM. ${ }^{10}$ In our patient also, a left lower lobectomy was done. Grossly, CPAM comprises single or multiple cysts of varying sizes containing purulent material suggestive of superadded infection. On microscopy, cystic air spaces lined by cuboidal-columnar epithelium are associated with tubular bronchiole-like structures with respiratory epithelium lining. ${ }^{9}$ A final diagnosis of CPAM-type 2-left lower lobe was made based on the history, clinical examination, radiological, gross, and microscopic findings.

Approximately, $80 \%$ of CPAMs are diagnosed prenatally or during the neonatal period when patients present with respiratory failure and cyanosis. CPAMs are rarely found in adults. The age ranges from 21 to 80 years, and their mean age was 38 years. It usually affects the lower lobes of the lungs.

Table 1 Salient clinicopathological characteristics of CPAM in neonates and adults

\begin{tabular}{|l|l|l|}
\hline & CPAM neonates & CPAM adults \\
\hline Associated type & Type $0,3,4$ & Type 1,2 \\
\hline Clinical manifestations & $\begin{array}{l}\text { Recurrent respiratory infections, } \\
\text { acute respiratory distress }\end{array}$ & $\begin{array}{l}\text { Recurrent pulmonary infection, } \\
\text { pneumothorax, hemoptysis, fever, and dyspnea }\end{array}$ \\
\hline Risk of malignancy & Nil & Rarely to adenocarcinoma \\
\hline
\end{tabular}

Abbreviation: CPAM, congenital pulmonary airway malformation. 
These manifests with infection or common respiratory symptoms like cough, sputum, or respiratory distress. Few patients present with pneumonia, lung abscesses, pulmonary tuberculosis, or aspergillosis. Few cases are associated with increased incidence of papillary or mucinous adenocarcinoma.

The following differentials have to be ruled out to avoid false diagnoses. Bronchopulmonary sequestration usually has no connection to the tracheobronchial tree. It is supplied by an anomalous systemic artery like the descending thoracic aorta or the abdominal aorta rather than the pulmonary circulation. The absence of anomalous vascularization in our case excludes bronchopulmonary sequestration. ${ }^{9-15}$ The lack of inflammatory destruction of cartilage and bronchi with squamous metaplasia ruled out the bronchogenic cyst. Esophageal duplication cyst shows an attachment to the esophageal wall. ${ }^{9-15}$ Usually, they have gastric epithelium and two layers of muscularis propria, which were absent in our case. ${ }^{14}$ Lungs are the second most common site for hydatid disease in adults. It becomes one of the common differentials for CPAM, which the laminated cyst and brood capsules can differentiate with scolices in our case. ${ }^{15}$ In addition to these, the differential diagnosis of CPAM also includes congenital diaphragmatic hernia, congenital lobar emphysema, localized pulmonary interstitial emphysema, and pneumatoceles due to staphylococcal infection. These disorders usually can be distinguished from CPAM based on radiographic appearance and clinical history. ${ }^{16-19}$

In most cases, the prognosis of CPAM after resection is favorable, and some rare cases have been reported showing patients developing mucinous bronchoalveolar carcinomas after resection. ${ }^{14-19}$ Considering the risk of malignant transformation, patients are regularly advised to follow up in 3 to 5 years. The postoperative event, in our case, was favorable, and the patient is doing well.

\section{Conclusion}

Due to the rarity of CPAM in adults and the presence of close mimickers, it is essential to consider CPAM as one of the differentials in patients with a cystic lesion of lung and recurrent respiratory tract infections.

Conflict of Interest

None declared.

\section{References}

1 Langston C. New concepts in the pathology of congenital lung malformations. Semin Pediatr Surg 2003;12(01):17-37
2 Gorospe L, Muñoz-Molina GM, Ayala-Carbonero AM, et al. Cystic adenomatoid malformation of the lung in adult patients: clinicoradiological features and management. Clin Imaging 2016;40 (03):517-522

3 Jones K, Dishop MK, Colby TV. Developmental and pediatric lung disease. In: Leslie KO, Wick MR, eds. Practical Pulmonary Pathology: A Diagnostic Approach. 2nd edition Philadelphia: Mosby Elsevier; 2011:91-116

4 Chikkannaiah P, Kangle R, Hawal M. Congenital cystic adenomatoid malformation of lung: report of two cases with review of literature. Lung India 2013;30(03):215-218

5 El Amraoui W, Bentalha A, Hamri H, Es-Chrif El Kettani S, El Koraichi A. Congenital cystic adenomatoid malformation - dangers of misdiagnosis: a case report. J Med Case Reports 2017;11 (01):212

6 Kagawa H, Miki K, Miki M, Urasaki K, Kitada S. Congenital cystic adenomatoid malformation in adults detected after infection. Respirol Case Rep 2018;6(08):e00364

7 Herrero Y, Pinilla I, Torres I, Nistal M, Pardo M, Gómez N. Cystic adenomatoid malformation of the lung presenting in adulthood. Ann Thorac Surg 2005;79(01):326-329

8 Stocker JT, Mani H, Husain AN. The respiratory tract. In: Stocker JT, Dehner LP, Husain AN, eds. Stocker and Dehner's Pediatric Pathology, 3rd edition. Philadelphia, PA: Lippincott, Williams \& Wilkins; 2011:441-515

9 Myers JL. Lung. In: Goldblum JR, Lamps LW, McKenney JK, Myers JL, eds. Rosai and Ackerman's Surgical Pathology. 11th edition Philadelphia: Mosby Elsevier; 2018:372-443

10 Scamporlino A, Ambrosini A, Turrini E, Morandi U, Stefani A. Congenital cystic adenomatoid malformation in adults, presenting as a single cyst. Asian Cardiovasc Thorac Ann 2018;26(05): 407-409

11 Feng A, Cai H, Sun Q, Zhang Y, Chen L, Meng F. Congenital cystic adenomatoid malformation of lung in adults: 2 rare cases report and review of the literature. Diagn Pathol 2012;7:37

12 Wong A, Vieten D, Singh S, Harvey JG, Holland AJ. Long-term outcome of asymptomatic patients with congenital cystic adenomatoid malformation. Pediatr Surg Int 2009;25(06):479-485

13 Durell J, Lakhoo K. Congenital cystic lesions of the lung. Early Hum Dev 2014;90(12):935-939

14 Yang J, Zhou T, Fu J, Zhang Y. Differentiation of esophageal duplication cysts from esophageal bronchogenic cysts: a case report and literature review. Transl Surg 2018;3:20-22

15 Iqbal N, Hussain M, Idress R, Irfan M. Disseminated hydatid cyst of liver and lung. BMJ Case Rep 2017;2017:1-3

16 Takeda S, Miyoshi S, Minami M, Ohta M, Masaoka A, Matsuda H. Clinical spectrum of mediastinal cysts. Chest 2003;124(01):125-132

17 Ursini WP, Ponce CC. Congenital pulmonary airway malformation. Autops Case Rep 2018;8(02):e2018022

18 Hamanaka R, Yagasaki H, Kohno M, Masuda R, Iwazaki M. Congenital cystic adenomatoid malformation in adults: report of a case presenting with a recurrent pneumothorax and a literature review of 60 cases. Respir Med Case Rep 2018; 26:328-332. Doi: 10.1016/j.rmcr.2018.02.002

19 Baral D, Adhikari B, Zaccarini D, Dongol RM, Sah B. Congenital pulmonary airway malformation in an adult male: a case report with literature review. Case Rep Pulmonol 2015;2015:743452 